\title{
ALGUMAS PARTICULARIDADES LINGÜISTICAS DE LARANJEIRAS DO SUL, PARANÁ (*)
}

THEREZINHA $M$. M. ANDREETTA

Natural do Rio Grande do Sul, da cidade de Erexim, onde residimos por mais de vinte anos, quando de nossa mudança para a cidade de Laranjeiras do Sul, Estado do Paraná, observamos algumas particularidades lingüísticas, e, achando-as dignas de nota, resolvemos recolhê-las, em ordem alfabética, agrupando-as de acôrdo com a fonte de pesquisa.

Diferencas lingüísticas existem em diversas localidades do Rio Grande do Sul, do Paraná e de outros Estados do Brasil. Ao lado dessas diferenças, porém, notamos particularidades semelhantes e próprias das diversas origens, bem como de cada Estado.

A linquagem de Laranjeiras do Sul apresenta pontos distintos da de Erexim, na fonética, no vocabulário, na morfologia, na sintaxe e na semântica. pectos.

Embora ràpidamente, procuraremos tratar dos diversos as-

\section{ASPECTO FONETICO}

Observamos diferenças, não só entre Erexim e Laranjeiras do Sul, como também entre a sede de Laranjeiras do Sul e os diversos distritos.

\section{Diferenças fonéticas entre Erexim e Laranjeiras do Sul (Sede)}

Na pronúncia de Laranjeiras do Sul:

(*) O presente estudo de Therezinha M. M. Andreetto, professôra de Português no Colégio Estodual de Laranjeiras do Sul, PR, foi-me entregue em 1964, mas, por vários motivos, só ajora vê a luz do publicação. Não é preciso encarecer a importôncia do trabalho, embora exiguo, e com diversas falhas fáceis de sanar. Espero que a colega amplie a pesquiso com novas aquisiçōes.

R. F. Mansur Guérios 
1 - O aberto: antes de consoante nasal, em palovras paroxitonas: fóme, cóme, nóme, telefóne. Em Erechim: $\mathbf{O}$ é fechado: antes de consoonte nasal, em palavras paroxitonas: fôme, côme, nôme, telefône.

2 - Na pronúncio de Laranjeiras do Sul: E permanece: nas palavras terminadas em de, te: dente, pente, onde.

Em Erexim: transforma-se em i: denti, penti, ondi.

3 - Nas localidades de Pôrto Sant'Ana e Nova Laranjeiras, onde há influência italiana:

a) O a tônico, seguido de $\mathbf{m}$, é aberto: cháma, cáma. (verão).

b) O ditongo ão tônico é pronunciado õ: põ, corraçõ, verrõ

c) Or intervocálico é uma vibrante múltipla: arreia, corraçõ, verrõ.

d) O rr, vibrante múltipla, é pronunciado simples: coria (corria), tera (terra), guera (guerra).

e) $O$ som $x$ é, muitas vêzes, pronunciado ss: bolassa (bolacho), sá (chá).

f) Em vez de seringa, dizem xeringa, e, por assimilação, xanxe, em vez de chance.

g) Pronunciom com o fechado: senhôra, agôra.

4 - Nas localidades de Pinhal Ralo e Espigão Alto, onde hó influência cabocla: (sal).

a) O I final é proferido r: mér (mel), sór (sol), mir (mil), sar

b) O I, em encontro consonantal, pronunciam r: brusa (blusa) carça (calça), vorta (volta), artura (altura), quarqué (qualquer), sarsa (salsa).

c) O tha pronunciam i: miio (milho), fôia (fôlha), fiio (filho), assoáio (assoalho), gáio (galho). (açúcar).

d) O r final não é pronunciado: cobertô (cobertor), açúca

\section{ASPECTO VOCABULAR}

$\mathrm{Na}$ designação das coisas e ações, nem sempre os laranjeirenses empregam os mesmas palovros e expressões que os erexinenses, o que poderemos verificar pela seguinte lista:

\section{LARANJEIRAS DO SUL}

adinchar fora

aipim

alfinête de segurança

barroco

bocudo

\section{EREXIM}

jogar ou botar fora

mandioca

joaninha

buraco

bôca grande 


$\begin{array}{ll}\text { bolear a bola } & \text { trilhar a corda } \\ \text { cabra } & \text { camarada } \\ \text { camarada } & \text { peão } \\ \text { carrinho } & \text { charrete ou aranha } \\ \text { carro } & \text { carroça } \\ \text { caminhonero ou caminhonzero } & \text { motorista } \\ \text { cheirinho verde } & \text { temperos verdes } \\ \text { dolé } & \text { picolé } \\ \text { dona } & \text { professôra } \\ \text { farinha de milho } & \text { biju } \\ \text { fubá } & \text { farinha de milho } \\ \text { garôto ou guri } & \text { piá } \\ \text { guardamento do morto } & \text { velório } \\ & \\ \text { LARANJEIRAS DO SUL } & \text { EREXIM } \\ \text { jagunço } & \text { capanga } \\ \text { marmita } & \text { vianda } \\ \text { meia para homem } & \text { carpim } \\ \text { meia para criança } & \text { soquete } \\ \text { meu chapa } & \text { amigo do peito } \\ \text { mimosa ou mexerica } & \text { bergamota ou vergamota } \\ \text { nenenzinho } & \text { nenêzinho } \\ \text { o cuque } & \text { a cuca } \\ \text { pressão de gancho } & \text { joaninha } \\ \text { quebrar o galho } & \text { resolver o problema } \\ \text { qual é o galho } & \text { qual é o problema } \\ \text { que só } & \text { só vendo } \\ \text { safra } & \text { engorda de porcos } \\ \text { safrista } & \text { suinocultor } \\ \text { setra ou estilingue } & \text { bodoque ou funda } \\ \text { traia } & \text { mudança } \\ \text { trigo } & \text { farinha de trigo } \\ \text { tongo } & \text { bôbo, louco } \\ \text { viúva } & \text { terçol } \\ \text { grampo } & \text { ramona } \\ & \\ & \end{array}$

\section{ASPECTO MORFOLOGICO}

1 - Em Laranjeiras do Sul, costumam pôr as palavras fácil e chovendo no grau diminutivo: facinho, chovendinho. niana:

2 - Em Campo Nôvo, onde há influência polonesa e ucra-

a) - Confundem o gênero dos substantivos. Ex.: o cidade.

b) - Dizem entertem por entretém; tremina por termina.

c) - Pronúncias diversas ou vocábulos diferentes, em Campo Nôvo: 
amanhum (amanhã)

bóia (comida)

bóca (bôca)

barracãozão (barracão)

cidadinha (cidade pequena)

Darucha (Dária) espulêto (espolêta, inquieta)

lóça (louça)

onteonte (anteontem)

sudade (saudades)

um par (diversos)

Zicha (Zilá)

3 - Em Nova Laranjeiras e Pôrto Sant'Ana, onde se noto influência italiana:

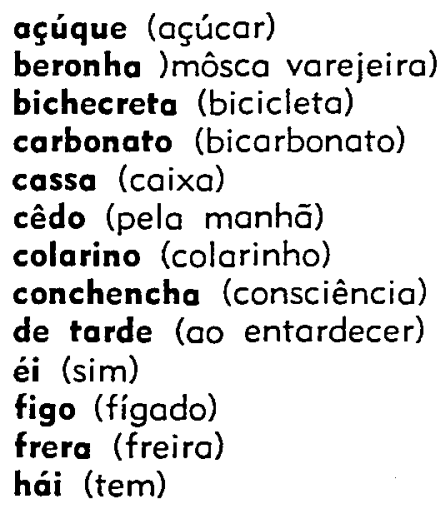

4 - Em Pinhal Ralo e Espigão Alto, onde se verifica influência cabocla:

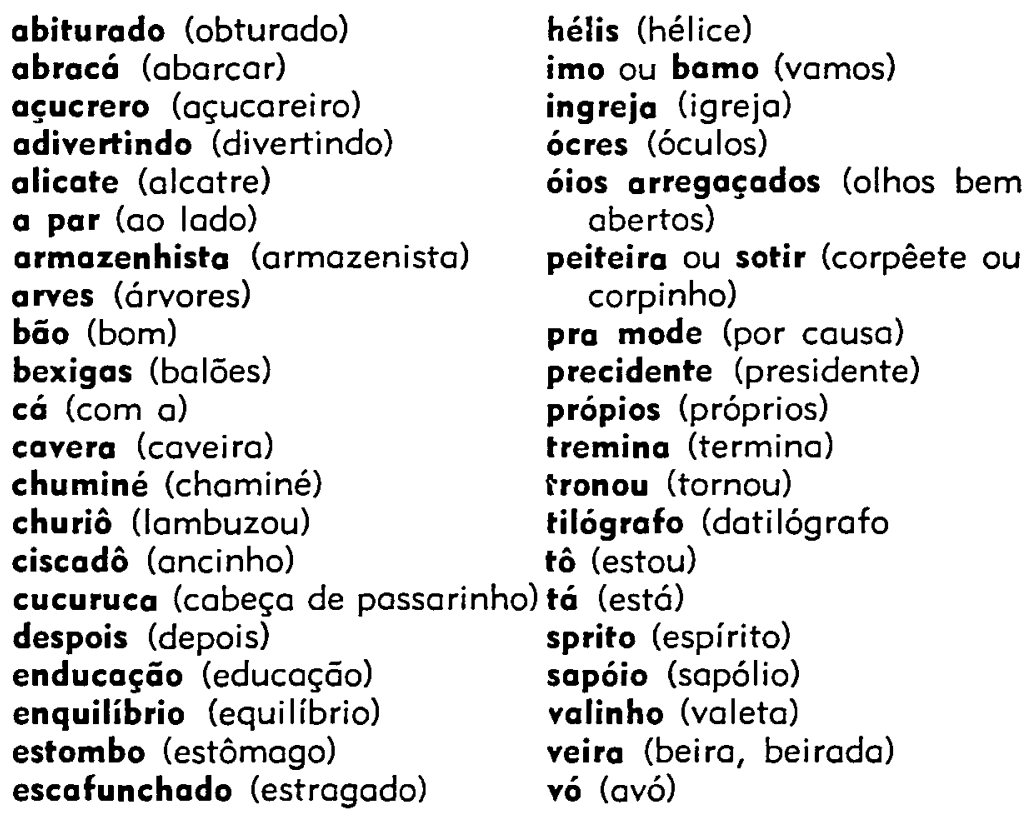


fósfre (fósforo)

jeção (injeção)

gíria (bôbo, louco)

gúia (agulha) viação (aviação)

vivero (viveram)

zoiúdo (olhudo)

\section{NA SINTAXE}

Notamos, também, algumas diferenças:

1) Loranjeiras do Sul: Erexim

Fulana está na casa. Fulano está em casa.

Deu ne mim. Deu em mim.

Dá de eu fazer? Dá para eu fazer?

2 - Em Laranjeiras do Sul usam, na linguagem familiar, o pronome de tratamento você, mas, em discordância, empregam te, ti, tigo, teu, tua, etc. Ex.: Você vai ao cinema com teu irmão.

Em Erexim usam o pronome tu, às vêzes, porém, com o verbo conjugado na $3 .^{\circ}$ pessoa do singular. Ex.: Tu vai ao cinema com teu irmão.

\section{3 - Em Campo Nôvo:}

está caminhando ou está an- (está frequientando as aulas) dando na escola

4 - Em Espigão Alto:

$\begin{array}{ll}\text { Entãoce bamo subi pra riba } & \text { (então vamos subir) } \\ \text { Amiúdá a lenha } & \text { (cortar mais fina a lenha) } \\ \text { Eu se esqueci } & \text { (eu me esqueci) }\end{array}$

\section{NA SEMÂNTICA}

Nem tôdas as palavras possuem a mesma significação. Exs.:

Dona: Em Laranjeiras do Sul quer dizer "professôra" e "senhora"; em Erexim, tem sentido pejorativo.

Farinha de milho: Em Laranjeiras do Sul, "biju, casquinha"; em Erexim, "fubá".

Safra: Em Laranjeiras do Sul, "engorda de porcos"; em Erexim, "época da colheita".

Campear: Em Laranjeiras do Sul, "procurar qualquer coisa" (Pinhal Ralo); em Erexim, "procurar animais no campo". 


\section{PRINCIPAIS FONTES INFORMATIVAS}

1) Natalina Moria Faccicola: 44 anos, origem italiona, Pôrto Sont'Ana;

2) Libera Faccicolo Perachi: 42 onos, origem italiona, Pôrto Sont'Ano;

3) Ângelo Zocchi: 40 anos, origem italiana, Pôrto Sant'Ano;

4) Guido de Lucca: 56 anos, origem italiana, Nova Laranjeiras;

5) Anastácia Welfer Vagocz: 34 anos, origem poloneso, Campo Nôvo;

6) Wieceslau Abromovicz: 45 anos, origem polonesa, Campo Nôvo;

7) Onofre Jacoboski: 17 anos, origem poloneso, Compo Nôvo;

8) Justina Gruba: 75 anos, arigem ucraniano, Campo Nôvo;

9) Isaura Grubo: 50 anos, origem ucraniana, Campo Nôvo;

10) Woldomiro Gruba: 56 onos, origem ucraniana, Campo Nôvo;

11) Ermelina Ribeiro de Lima: 42 anos, Espigāo Alto, origem caboclo;

12) Ana do Silva: 68 anos, cabocla, Espigão Alto;

13) Eugènio Ribeiro de Lima: 26 onos, caboclo, Pinhal Ralo;

14) Manuel do Luz: 60 anos, caboclo, Pinhal Rolo;

15) Guilhermina da Silva: 64 anos, cabocla, Sede.

16) Pedro Gomes da Silva: 66 anos, caboclo, Sede.

\section{BIBLIOGRAFIA}

Em vista da natureza do assunto, deixamos de apresentar bibliografia, porquanto é trabalho de pesquisa "in loco", e não há bibliografia.

Loranjeiros do Sul, 26 de maio de 1964. 